\title{
Preceptor Expectations and Experiences in a Longitudinal Integrated Clerkship
}

\author{
Zachary Tabb, BS | Kristina Monteiro, PhD | Paul George, MD, MHPE \\ Published: 1/10/2018 | DOI: 10.22454/PRiMER.2018.824638
}

\section{Abstract}

Introduction: The Longitudinal Integrated Clerkship (LIC) as a pedagogical model in medical education is a burgeoning area of interest as an alternative to a traditional, rotation- (block) based curriculum and presents a distinct set of considerations. A large number of studies examine the impact on students participating in LIC programs, but fewer assessments exist for the preceptors involved. This study sought to understand changes in expectations and experiences following LIC program participation.

Methods: We conducted a survey-based prospective cohort study of preceptors before and after first-time LIC program participation. Five-point Likert-type questions were grouped into four subscales determined by areas of practice and preceptor role: clinical, administrative, professional, and educational. For statistical analyses of the nonmatched responses we used Pearson Chi-Square measures of association and independent $t$-tests.

Results: Forty-seven of $84(56 \%)$ preceptors responded to the presurvey and $42 \%$ responded to the postsurvey (35/84), totaling 82 unique responses. Thirty-nine (48\%) were female, $64(79 \%)$ had over 5 years teaching experience, and 61 (74\%) had prior rotation-based clerkship experience. Only the clinical subscale (evaluating aspects of physical exam, history taking, and patient relationship with physician and student) was significantly different pre- $(M 1=3.09[S D=0.40])$ to post-LIC $(M 2=3.47[S D=0.29])$ showing a positive change at post-LIC participation $(P=0.03)$.

Conclusion: For first-time LIC preceptors in a new LIC program, participation led to improvements in clinical practice without detriment to administrative, professional, or educational roles. Future research should examine changes among individual preceptors over time as well as assessments of students, including knowledge, skills, and attitude outcomes.

\section{Introduction}

Following the Flexner Report in 1910, little changed in the model of medical education until 1971 when the University of Minnesota implemented the first model of the longitudinal integrated clerkship (LIC). ${ }^{1}$ Similar models now exist globally in Australia, Canada, South Africa, and the United States, and have become increasingly prevalent in undergraduate medical education. ${ }^{2}$ The LIC model design focuses on continuity within each of the core disciplines, with learners undertaking multiple disciplines during the same time frame, as an alternative to the traditional rotation-based clinical experience in which a student focuses on a single discipline before moving on to the next. Consequently for preceptors, the exposure to the same student extends over the duration of an academic year, rather than a series of shorter exchanges multiple times over the same period. This model creates an opportunity for preceptors to work with a learner through the growth of their knowledge, skills, and confidence in a way not possible in the limited interactions of the rotation-based model.

As the popularity of this pedagogical model spreads, its impact is being increasingly examined. For their part, LIC 
students do as well as or better than traditional rotation-based students on national standardized exams, are more likely to maintain patient-centeredness and humanism, take more ownership over patient care, and express greater confidence in managing the challenges of the health care system. ${ }^{2-4}$ While much of the focus has been on the learners in the LIC curricula, less attention has been paid to preceptors and the impact on preceptors who participate in the program. Existing studies examine effects of the LIC on providers' length of patient visit with mixed results, while other studies report LIC preceptors experiencing higher professional satisfaction and improved teaching skills. ${ }^{3,5-7}$ Results are noted to change over the course of the program, ${ }^{8}$ with challenges early, but more positive experiences as participation continues. Studies examining faculty often consist of qualitative reflections of program participation, rather than quantitative longitudinal assessments, making it challenging to draw objective conclusions.

Further research is needed to better understand how aspects of preceptor time, satisfaction, and skills are impacted through LIC participation. We sought to better understand the changes in expectations, clinical practice, and precepting dynamics following participation in an LIC program.

\section{Methods}

We conducted a prospective cohort study of faculty from The Warren Alpert Medical School of Brown University before and after first-time participation in an LIC program over the 2015-2016 and 2016-2017 academic years. All active LIC faculty each academic year were invited to complete the questionnaire before and after the program. The full questionnaire can be found in the STFM Resource Library. ${ }^{9}$

The survey consisted of 22, 5-point Likert-type questions ( 1 =negative outcome, 5 =positive outcome), grouped into four subscales with questions targeting the preceptor him/herself focused on areas of practice and preceptor role: clinical, administrative, professional, and educational (Table 1). Inclusion criteria were any first-time LIC faculty willing to participate. No incentive was given for participation. Surveys were distributed using Google Forms and were anonymous.

Stata/SE 14.1 was used for statistical analyses of nonmatched responses to perform Pearson Chi-Square measures of association and independent $t$-tests. The Institutional Review Board of Brown University exempted the study of review.

\section{Results}

Of 84 faculty from two academic years, 47 (56\%) faculty completed the presurvey, 35 (42\%) completed the postsurvey, and demographics were similar between those who responded before and after participation (Table 2). Approximately half were female, $82 \%$ had practiced more than 5 years, $79 \%$ had more than 5 years teaching experience, and $74 \%$ had previously participated in a rotation-based clerkship.

Of the survey subscales, only the change in clinical subscale from pre- $(M=3.09, S D=0.40)$ to post- $(M=3.27$, $\mathrm{SD}=0.29)$ was statistically significant, showing positive change $(P=0.03$; Table 3$)$. Analysis of the individual question items comprising the clinical subscale is shown in Table 4.

\section{Discussion}

We sought to understand changes in the roles and practice of preceptors from participation in a new longitudinal integrated clerkship curriculum. For first-time LIC preceptors, participation led to improvements in clinical professional aspects without detriment to administrative, professional, or educational roles, as defined here. The majority of preceptors were in practice more than 5 years, suggesting an experienced clinical and administrative environment for incorporating student learners. Moreover, the majority had previously participated in rotation-based clerkship and had more than 5 years of teaching experience, suggesting preceptors had sufficient experience teaching medical students. 
Only the clinical subscale showed significant change in our study, with an improvement demonstrated following LIC participation. We hypothesize that, compared to the other subscales, the questions comprising this subscale address areas more readily influenced by changes in the learners' abilities across the academic year, in turn having a more notable impact on the preceptor. For example, history-taking and the physical exam by the preceptor at the beginning of the year is likely to require more time as the student is just beginning practical learning, compared to the end of the academic year, as was suggested by our findings. There is likely more initial investment, but as the year progresses, the learner becomes more knowledgeable and skillful, as well as more trusted by the preceptor, thereby requiring less time for clinical tasks. It seems reasonable that with each year of participation, preceptors would better define their role, gauge how to educate over an entire academic year, and understand how to optimally incorporate the student into the clinical practice. Together, these would be a unique assortment of lessons for the preceptor as compared to those found in rotation-based clerkship, namely because of the longitudinal design. Family medicine physicians might be best poised to gain from the LIC model over the course of the year as students gain experience in each of the individual medical fields, returning to clinic with the breadth and depth requisite to be effective family medicine physicians. Examining the pre- to post-LIC changes in the individual subscale questions, it appears that some items trended toward improvement more than others. It may be that certain items are driving the overall subscale significant result. However, due to needing such a large sample size to conduct formal scale development and analysis (which would include a principal components analysis and a confirmatory factor analysis), the individual clinical subscale analysis is beyond the scope of this study. Future research should further investigate the changing clinical picture across the LIC academic year.

Our study design only examined first-time LIC preceptors, which possibly helps to explain why nonsignificant differences were noted in three of the subscales. Following the same preceptors longitudinally across multiple years would result in valuable insight into the impact of LIC participation. Some survey questions (eg, satisfaction with teaching) might be harder to capture shifts for first-time preceptors in a new LIC program. On the other hand, question items such as showcasing one's field to the student, professional satisfaction, and relationship with colleagues (professional subscale) as well as other items such as teaching skills and satisfaction, serving as advisor, and sufficient teaching time (educational subscale) are possibly more preestablished in the preceptor, especially in the population sampled here who have extensive experience as practitioners and teachers. Other areas, such as changes in productivity or income (administrative subscale), might be more resilient against change when the learner is in each clinic only one half-day per week, as occurs in the LIC program examined here. The absence of demonstrated significant change in the subscales can in another view be seen as reassuring; a new pedagogical model, vastly different from the traditional model, can be well-adopted by preceptors.

There are limitations to our findings. Our study did not match pre- and post-LIC surveys from preceptors, so individual changes could not be assessed. We examined only first-year LIC preceptors, limiting our generalizability to subsequent years. While we have documented significant changes, physicians' challenges in self-evaluation may limit our findings. ${ }^{10}$ We report subjective quantitative findings of preceptor perspectives, and future research should examine more objective data on LIC participation, such as changes in patient volume or preceptor income. We used a pre/post-survey model, however because the surveys were completed approximately a year apart, it is unlikely pre/post-bias affected our results. Our study found improvements in clinical practice without detriment to administrative, professional, or educational roles for first-time LIC preceptors. Future research should examine changes among individual preceptors over time as well as assessments of students, including knowledge, skills, and attitudinal outcomes. In spite of these limitations, this study provides data that having an LIC student may benefit clinical practice, without detriment to other aspects of a physician's practice. 


\section{Tables and Figures}

Table 1: Questionnaire Subscale Individual Areas of Focus

\begin{tabular}{|c|c|}
\hline Subscale & Areas of Focus \\
\hline Clinical & $\begin{array}{ll}\text { - } & \text { physical exam skills } \\
\text { - } & \text { history taking } \\
\text { - } & \text { student bentient relationship } \\
\text { : } & \text { time with patient } \\
\text { - } & \text { physical exam time } \\
\text { history-taking time }\end{array}$ \\
\hline Administrative & $\begin{array}{ll}\text { - } & \text { productivity } \\
\text { - } & \text { efficiency } \\
\text { - } & \text { income } \\
& \text { responsibilities }\end{array}$ \\
\hline Professional & $\begin{array}{ll}\text { - } & \text { showcase field to student } \\
\text { - } & \text { giving back to profession } \\
\text { - } & \text { relatessional satisfaction } \\
& \text { relationship with colleagues with patients }\end{array}$ \\
\hline Educational & $\begin{array}{ll}\text { - } & \text { teaching skills } \\
\text { - } & \text { teaching satisfaction } \\
\text { - } & \text { sufficient teaching time } \\
\text { - } & \text { serve as advisor } \\
\text { student valued as team member } & \text { satisfaction with educational component of job }\end{array}$ \\
\hline
\end{tabular}

Questions were structured as 5-point Likert scales (1=negative outcome, 5=positive outcome). Subscale scores were calculated from responses to individual questions regarding areas of focus. 
Table 2: Preceptor Characteristics and Results of Pearson Chi-Squared Measures of Association

\begin{tabular}{|c|c|c|c|c|c|c|c|}
\hline \multirow[t]{2}{*}{ Characteristics } & \multicolumn{2}{|c|}{ Total } & \multicolumn{2}{|c|}{$\begin{array}{c}\text { Pre-LIC } \\
(\mathrm{N}=47)\end{array}$} & \multicolumn{2}{|c|}{$\begin{array}{c}\text { Post-LIC } \\
(\mathrm{N}=35)\end{array}$} & \multirow[t]{2}{*}{$\boldsymbol{P} \ddagger$} \\
\hline & No. & $\%$ & No. & $\%$ & No. & $\%$ & \\
\hline \multicolumn{8}{|l|}{ Gender } \\
\hline Female & 39 & 47.6 & 21 & 44.7 & 18 & 51.4 & \\
\hline Male & 43 & 52.4 & 26 & 55.3 & 17 & 48.6 & \\
\hline Total & 82 & 100.0 & 47 & 100.0 & 35 & 100.0 & 0.55 \\
\hline \multicolumn{8}{|l|}{ Age, yrs } \\
\hline $26-34$ & 7 & 8.8 & 4 & 8.9 & 3 & 8.6 & \\
\hline $35-44$ & 22 & 27.5 & 13 & 28.9 & 9 & 25.7 & \\
\hline $45-54$ & 26 & 32.5 & 16 & 35.6 & 10 & 28.6 & \\
\hline$>1=55$ & 25 & 31.3 & 12 & 26.7 & 13 & 37.1 & \\
\hline Total & 80 & 100.0 & 45 & 100.0 & 35 & 100.0 & 0.79 \\
\hline \multicolumn{8}{|l|}{ Medical Field } \\
\hline Family medicine & 14 & 17.5 & 8 & 17.4 & 6 & 17.6 & \\
\hline Internal medicine & 11 & 13.8 & 6 & 13.0 & 5 & 14.7 & \\
\hline OB/GYN & 9 & 11.3 & 6 & 13.0 & 3 & 8.8 & \\
\hline Pediatrics & 20 & 25.0 & 10 & 21.7 & 10 & 29.4 & \\
\hline Psychiatry & 14 & 17.5 & 9 & 19.6 & 5 & 14.7 & \\
\hline Neurology & 5 & 6.3 & 3 & 6.5 & 2 & 5.9 & \\
\hline Surgery & 7 & 8.8 & 4 & 8.7 & 3 & 8.8 & \\
\hline Total & 80 & 100.0 & 46 & 100.0 & 34 & 100.0 & 0.98 \\
\hline \multicolumn{8}{|l|}{ Years in Practice } \\
\hline $0-5$ & 14 & 17.7 & 8 & 17.8 & 6 & 17.6 & \\
\hline $6-10$ & 14 & 17.7 & 8 & 17.8 & 6 & 17.6 & \\
\hline $11-15$ & 9 & 11.4 & 4 & 8.9 & 5 & 14.7 & \\
\hline $15+$ & 42 & 53.2 & 25 & 55.6 & 17 & 50.0 & \\
\hline Total & 79 & 100.0 & 45 & 100.0 & 34 & 100.0 & 0.88 \\
\hline \multicolumn{8}{|l|}{ Years Teaching } \\
\hline $0-5$ & 17 & 21.0 & 11 & 23.9 & 6 & 17.1 & \\
\hline $6-10$ & 13 & 16.0 & 6 & 13.0 & 7 & 20.0 & \\
\hline $11-15$ & 12 & 14.8 & 7 & 15.2 & 5 & 14.3 & \\
\hline $15+$ & 39 & 48.1 & 22 & 47.8 & 17 & 48.6 & \\
\hline Total & 81 & 100.0 & 46 & 100.0 & 35 & 100.0 & 0.79 \\
\hline \multicolumn{8}{|c|}{$\begin{array}{l}\text { Previous Participation in } \\
\text { Rotation-based Clerkship }\end{array}$} \\
\hline No & 21 & 25.6 & 9 & 19.1 & 12 & 34.3 & \\
\hline Yes & 61 & 74.4 & 38 & 80.9 & 23 & 65.7 & \\
\hline Total & 82 & 100.0 & 47 & 100.0 & 35 & 100.0 & 0.12 \\
\hline
\end{tabular}

${ }^{\ddagger} X^{2}$ comparing pre- and post-LIC respondents 
Table 3: Results of Independent $t$-tests on Pre- and Post-LIC Subscales

\begin{tabular}{|c|c|c|c|c|c|c|c|}
\hline \multirow[t]{2}{*}{ Subscale } & \multicolumn{3}{|c|}{ Pre-LIC ${ }^{+}$} & \multicolumn{3}{|c|}{ Post-LIC ${ }^{\ddagger}$} & \multirow[t]{2}{*}{$P$} \\
\hline & $\mathbf{N}$ & $\begin{array}{c}\text { Mean } \\
\text { (SD) }\end{array}$ & $95 \% \mathrm{Cl}$ & $\mathbf{N}$ & $\begin{array}{c}\text { Mean } \\
\text { (SD) }\end{array}$ & $95 \% \mathrm{Cl}$ & \\
\hline Clinical $^{a}$ & 992 & $3.09(0.40)$ & $2.97-3.21$ & 790 & $3.27(0.29)$ & $3.17-3.37$ & 0.027 \\
\hline Administrative $^{\mathrm{b}}$ & 487 & $2.59(0.48)$ & $2.45-2.73$ & 340 & $2.47(0.43)$ & 2.32-2.61 & 0.228 \\
\hline Professionalc & 866 & $3.70(0.51)$ & $3.56-3.85$ & 635 & $3.65(0.43)$ & $3.50-3.79$ & 0.583 \\
\hline Educationald $^{d}$ & 1,112 & $3.96(0.52)$ & $3.80-4.11$ & 790 & $3.76(0.48)$ & $3.60-3.93$ & 0.087 \\
\hline
\end{tabular}

Questions were structured as 5-point Likert scales (1=negative outcome, 5=positive outcome). Cumulative score (N), mean, standard deviation (SD), and the 95\% $\mathrm{Cl}$ of all respondents' answers are provided for each subscale at pre- and post-LIC evaluation

$+=47$ pre-test respondents

$\ddagger=35$ post-test respondents

a contains 7 questions (physical exam skills, history taking, doctor-patient relationship, student benefitting patients, time with patient, physical exam time, historytaking time)

${ }^{\mathrm{b}}$ contains 4 questions (productivity, efficiency, income, responsibilities)

${ }^{c}$ contains 5 questions (showcase field to student, giving back to profession, professional satisfaction, relationship with colleagues, relationship with patients)

${ }^{\text {a }}$ contains 6 questions (teaching skills, teaching satisfaction, sufficient teaching time, serve as advisor, student valued team member, and satisfaction with educational component of job)

Table 4: Clinical Subscale Individual Question Scores by Pre- and Post-LIC

\begin{tabular}{|c|c|c|c|c|c|c|}
\hline \multirow{2}{*}{ Survey Item } & \multicolumn{4}{|c|}{ Pre-LIC } & \multicolumn{3}{c|}{ Post-LIC } \\
\cline { 2 - 7 } & N & Median & Mean (SD) & N & Median & Mean (SD) \\
\hline Physical exam skills & 46 & 3.00 & $3.39(0.77)$ & 35 & 3.00 & $3.20(0.58)$ \\
\hline My ability to take a patient history & 47 & 3.00 & $3.19(0.68)$ & 35 & 3.00 & $3.11(0.58)$ \\
\hline The impact on my doctor-patient relationships & 47 & 4.00 & $3.60(0.71)$ & 35 & 4.00 & $3.54(0.61)$ \\
\hline $\begin{array}{c}\text { The likelihood of a student benefiting patients } \\
\text { in my practice }\end{array}$ & 43 & 4.00 & $3.67(0.87)$ & 35 & 4.00 & $3.91(0.70)$ \\
\hline $\begin{array}{c}\text { The length of time I spend with a patient } \\
\text { changing }\end{array}$ & 47 & 2.00 & $2.55(0.72)$ & 35 & 3.00 & $2.97(0.82)$ \\
\hline $\begin{array}{c}\text { The length of time I spend performing a } \\
\text { physical exam changing }\end{array}$ & 46 & 2.50 & $2.61(0.71)$ & 34 & 3.00 & $2.97(0.52)$ \\
\hline $\begin{array}{c}\text { The length of time I spend taking a patient } \\
\text { history changing }\end{array}$ & 45 & 3.00 & $2.64(0.71)$ & 33 & 3.00 & $3.12(0.82)$ \\
\hline
\end{tabular}

Questions were structured as 5-point Likert scales (1=negative outcome, 5=positive outcome). Question items that were included in the clinical subscale along with respondents $(\mathrm{N})$, median, mean and standard deviation (SD) are shown.

\section{Corresponding Author}

Zachary Tabb, BS

222 Richmond Street, Providence, RI 02906

Zachary_Tabb@Brown.edu

\section{Author Affiliations}

Zachary Tabb, BS - The Alpert Medical School of Brown University

Kristina Monteiro, PhD - The Alpert Medical School of Brown University

Paul George, MD, MHPE - The Alpert Medical School of Brown University

\section{References}

1. Strasser R, Hirsh D. Longitudinal integrated clerkships: transforming medical education worldwide? Med Educ. 2011;45(5):436-437.

https://doi.org/10.1111/j.1365-2923.2011.03939.x. 
2. Norris TE, Schaad DC, DeWitt D, Ogur B, Hunt DD; Consortium of Longitudinal Integrated Clerkships. Longitudinal integrated clerkships for medical students: an innovation adopted by medical schools in Australia, Canada, South Africa, and the United States. Acad Med. 2009;84(7):902-907. https://doi.org/10.1097/ACM.0b013e3181a85776.

3. Ogur B, Hirsh D, Krupat E, Bor D. The Harvard Medical School-Cambridge integrated clerkship: an innovative model of clinical education. Acad Med. 2007;82(4):397-404. https://doi.org/10.1097/ACM.0b013e31803338f0.

4. Walters L, Greenhill J, Richards J, et al. Outcomes of longitudinal integrated clinical placements for students, clinicians and society. Med Educ. 2012;46(11):1028-1041. https://doi.org/10.1111/j.1365-2923.2012.04331.x.

5. Walters L, Worley P, Prideaux D, Lange K. Do consultations in rural general practice take more time when practitioners are precepting medical students? Med Educ. 2008;42(1):69-73. https://doi.org/10.1111/j.1365-2923.2007.02949.x.

6. Teherani A, O'Brien BC, Masters DE, Poncelet AN, Robertson PA, Hauer KE. Burden, responsibility, and reward: preceptor experiences with the continuity of teaching in a longitudinal integrated clerkship. Acad Med. 2009;84(10)(suppl):S50-S53. https://doi.org/10.1097/ACM.0b013e3181b38b01.

7. Snow SC, Gong J, Adams JE. Faculty experience and engagement in a longitudinal integrated clerkship. Med Teach. 2017;39(5):527-534. https://doi.org/10.1080/0142159X.2017.1297528.

8. Walters L, Prideaux D, Worley P, Greenhill J. Demonstrating the value of longitudinal integrated placements to general practice preceptors. Med Educ. 2011;45(5):455-463. https://doi.org/10.1111/j.1365-2923.2010.03901.x.

9. Tabb Z, George P. LIC Preceptor Questionnaire. STFM Resource Library. https://resourcelibrary.stfm.org /viewdocument/lic-program-participation-survey. Accessed January 2018.

10. Davis DA, Mazmanian PE, Fordis M, Van Harrison R, Thorpe KE, Perrier L. Accuracy of physician selfassessment compared with observed measures of competence: a systematic review. JAMA. 2006;296(9):1094-1102. https://doi.org/10.1001/jama.296.9.1094.

Copyright $@ 2018$ by the Society of Teachers of Family Medicine 